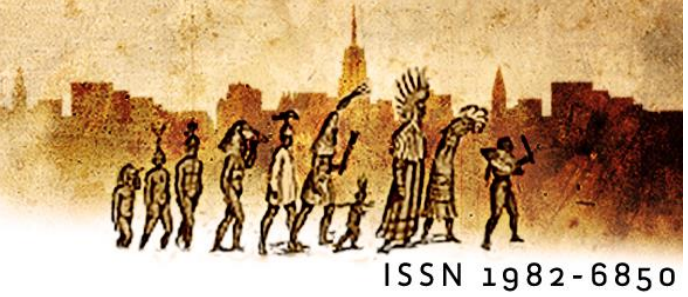

\title{
La representación novelística de la realidad americana en Tirano Banderas: Indeterminación referencial e intencionalidad política
}

\author{
Carlos Ferrer Plazai (UFV)
}

\begin{abstract}
Resumen: Ramón del Valle-Inclán realizó en su novela Tirano Banderas (1926) una recreación literaria de la realidad hispanoamericana que ha provocado, desde su publicación, reacciones de muy distinto signo sobre su interpretación de las claves histórico-sociales y culturales del continente. EI presente artículo analiza los mecanismos novelescos utilizados por el autor para realizar esta representación, logrando abrir nuevos caminos para la narrativa política en lengua española. Para ello, basaremos nuestro análisis de la obra en la propuesta teórica expuesta por Benjamín Harshaw (1997) sobre "Campos de Referencia", y los estudios monográficos sobre la novela publicados por Dougherty (1983), Díaz Migoyo (1985) y Zamora Vicente (1999).

Palabras clave: Valle-Inclán; Tirano Banderas; indeterminación referencial; Benjamín Harshaw
\end{abstract}

\begin{abstract}
Ramón del Valle-Inclán produced in his novel Tirano Banderas (1926) a literary recreation of Spanish-American reality. Since the novel was published, it has provoked differing reactions to its interpretation of the continental socio-historical and cultural key issues. The main objective of this article is to analyze the novelistic mechanisms that Valle-Inclán used to create his representation, which may well have opened new paths for Spanish-language political fiction. For this purpose, the analysis of the novel will be based on the platform offered by Benjamin Harshaw's 1997 theory of the Fields of Reference, as well as on the monographs on the novel published by Dougherty (1983), DíazMigoyo (1985) y Zamora Vicente (1999).

Key-words: Valle-Inclán; Tirano Banderas; referentialindeterminacy; Benjamín Harshaw
\end{abstract}

Tirano Banderas. Novela de tierra caliente, de Ramón María del Valle-Inclán, se publica en Madrid el 15 de diciembre de 1926. Considerada una de las mejores novelas 
de su autor ${ }^{1}$, ha sido objeto, prácticamente desde su publicación, de una atención privilegiada por parte de la crítica ocupada en la creación literaria valleinclanesca. El extenso número de trabajos dedicados a la obra reflejan la complejidad y originalidad de la novela tanto en sus aspectos formales como en su significación ideológica y política.

Entre los enfoques más relevantes adoptados por la crítica a la hora de analizar Tirano Banderas destaca la importante influencia que ejerció en la novela hispanoamericana del siglo $X X$, especialmente sobre el subgénero novelístico denominado "novela de(l) dictador", del que Tirano Banderasha sido considerado texto precursor. Este hecho provoca que el fenómeno que voy a exponer a continuación sea, por contradictorio, extremamente significativo. Me refiero a la valoración frecuentemente negativa que ha realizado una importante parte de la crítica a la hora de evaluar el retrato novelesco que Valle-Inclán hace de la realidad hispanoamericana. Este punto de vista provoca en muchos casos la minimización de su importancia como precedente de la novelística con temática dictatorial escrita en el continente o incluso de la trascendencia de sus hallazgos formales. Además, estas opiniones negativas provocan un interés aún mayor al contrastarlas con otras críticas con afirmaciones diametralmente opuestas, en las que la recreación de un mundo americano realizada por el autor gallego en Tirano Banderas es interpretada como un importante logro literario.

Los ejemplos de esta polémica crítica son numerosos, recordemos algunos: comenzando por Giuseppe Bellini (2000), que, al comparar la obra El Señor Presidentede Miguel Ángel Asturias con la novela de Valle-Inclán, afirma que al texto del autor gallego le falta "una experiencia directa del dolor" (2000, p. 22); o la valoración de Mario Benedetti, para el que Tirano Banderas "aunque está imaginada a partir de concretas realidades latinoamericanas, deja al descubierto que ha sido concebida desde Europa" (1979, p. 12), el escritor uruguayo tambiénseñala la falta de conocimiento directo de Valle-Inclán sobre lo que es realmente una dictadura hispanoamericana y enfatiza la condición de extranjero del escritor gallego, su visión

\footnotetext{
${ }^{1}$ El propio Valle-Inclán estaba plenamente satisfecho de su creación, como denotan las palabras de orgullo con las que se refería a la novela: "Lo que he escrito antes de Tirano Banderas es musiquilla de violín. Esta novela es la primera que escribo. Mi labor empieza ahora" (apud ZAMORA VICENTE, 1999, p. 25).
} 
desde fuera, lo que supuestamente provocaría una cierta inautenticidad a la hora de representar esta realidad.Con anterioridad a estos dos estudios, Ricardo Navas Ruiz (1962) ya había expresado reticencias a la propuesta de Valle-Inclán en la misma línea de Bellini y Benedetti, inclinándose por la postura más crítica con la obra de ValleInclán, "la de aquellos que ven en Tirano Banderas una americanada" (1962, p. 57). También incide en esa valoración negativa Seymour Menton, en su célebre artículo"La novela experimental y la república comprensiva de Hispanoamérica" (1969) el conocimiento de la realidad hispanoamericana que posee Valle-Inclán es comparado con el de autores como Joseph Conrad y Francis de Miomandre, "aunque Hispanoamérica en algunos casos quedaba casi igualmente remota y fantástica para el español Valle-Inclán" (p. 249).

Lo más sorprendente de todas estas interpretaciones es constatar la tendencia de otra parte de la crítica que, en trabajos publicados de manera casi simultánea a los anteriormente mencionados, realiza una interpretación completamente diferente -e incluso exactamente contraria- del mismo objeto de estudio. De esta manera Conrado Zuloaga, en 1977, afirma que "la Novela de Tierra Caliente de Valle-Inclán permanece como la mejor novela del dictador, la que logra captar una realidad y recrearla(1977, p. 15) y, en un texto de 1957, Juan Liscano explica que "si Valle-Inclán escribió un libro semejante fue porque visitó América no como turista de la literatura [...], sino como enamorado de esos paisajes de Génesis y de esa humanidad contradictoria y pasional" (2000, p. 796).

Es interesante observar cómo este fenómeno se configura y desarrolla ya en las interpretaciones surgidas a raíz de la publicación de la novela y en los años inmediatamente posteriores a su aparición. En general la recepción crítica de la obra fue de perplejidad y desorientación ante las novedades formales que presentaba, dividiéndose entre aquellos críticos que valoraron la obra como un fracaso en su tentativa de mostrar la realidad hispanoamericana y aquellos que intentaron entender y explicar sus innovaciones formales, asignándoles un sentido trascendente más allá del juego esteticista. El escritor venezolano Rufino Blanco Fombona dedica en 1927 una reseña a la novelatitulada "En torno a Tirano Banderas" en la que dejó plasmado su rechazo hacia lo que él denomina "una América de pandereta" (1927, s.p.). Ese mismo año, Martín Luis Guzmán (2011) escribe también una reseña de la novela en la 
que el autor mexicano parece intuir la divergencia de opiniones que la novela de ValleInclán provocará en el futuro entre sus lectores y críticos:

La última novela de Valle-Inclán -Tirano Banderas- será juzgada, probablemente, según dos criterios diversos $y_{1}$ en parte, inconciliables: uno será el criterio español; otro, el hispanoamericano. Conforme al primero habrá quienes descubran en esta "novela de tierra caliente" -con plena justicia- una síntesis admirable de la América esencial, en el sentido de que hay una esencia última de España en Luces de Bohemia o en La farsa y licencia de la reina castiza. Conforme el segundo, habrá los que perciban allí, en vez de la esencia, la caricatura. (GUZMÁN, 2011, p. 102).

En contraste con las opiniones de Blanco Fombona -y en menor medida con las de Martín Luis Guzmán-, la interpretación que el pensador mexicano Pedro Henríquez Ureña expone en un ensayo de 1936 titulado "Don Ramón del Valle-Inclán" (1996) es radicalmente diferente. El pensador dominicano, que había acompañado a Valle-Inclán en el viaje que este había realizado por México en 1921, defiende la interiorización de una América vivida íntimamente por parte del autor de Tirano Banderas y la demostrada capacidad de encontrar "la esencia de lo americano" a través de una estética que "busca los arquetipos" (1996, p. 380). Además, Henríquez Ureña aprecia en la perspectiva adoptada en la novela un equilibrio cuya perfección le causa extrañeza:

La obra estiliza con rara perfección acontecimientos típicos de la vida pública en la América española. Rara perfección, en que el autor vive la vida de su novela en el plano de la contemplación purificadora, sin participación apasionada como la que hincha de indignación las páginas de Amalia, pero sin la fría distancia presuntuosa, engendradora del desdén y la sátira. (GUZMÁN, 1996, p. 380)

En mi opinión, es aquí donde encontramos una de las claves de este debate crítico en torno a la novela que recorre todo el siglo XX. El equilibrio al que se refiere Henríquez Ureña es "raro" porque no se mantiene en función de una estudiada proporción entre el cuidado esteticista de la forma y el material documental que toda obra de carácter político -referida a una realidad tan presente y dolorosa como las dictaduras hispanoamericanas- supuestamente requería. Este equilibrio tiene su 
fundamento en un radical cambio de rumbo literario que difícilmente fue comprendido entre los contemporáneos de Valle-Inclán o que, en su defecto, fue considerado, incluso décadas después, frío, artificioso, esteticista, excesivamente distanciado. Nos encontramos ante una narrativa política que sitúa en el centro de la novela los aspectos puramente literarios, manipulando artísticamente la realidad histórica referencial y sustituyéndola por otro eje central en la obra: el propio lenguaje.

La introducción de lo irracional y fantástico en la novela, junto a la práctica de estéticas de vanguardia como la cubista y expresionista, llenan de ambigüedad la relación entre el texto literario y su referente histórico, convirtiendo al tratamiento literario de aspectos como espacio, tiempo y lenguaje en un factor decisivo en la relación de la novela con el mundo objetivo. Problematizando así la realidad desde el propio lenguaje, la narrativa política abre su abanico de posibilidades a caminos capaces de superar el excesivo proselitismo que mermaba su potencialidad artística.

Creo que un abordaje que pretenda analizar la novela de Valle-Inclán desde esta perspectiva, en la que el referente realista es sustituido por el propio lenguaje como eje estructurador de la novela, debe profundizar en los mecanismos que rigen las relaciones entre la realidad americana y su representación narrativa, cuya clave estaría, a mi modo de ver, en lo que he denominado "indeterminación referencial". Para desarrollar este abordaje interpretativo considero pertinente utilizar la propuesta teórica expuesta por Benjamín Harshaw en su artículo "Ficcionalidad y campos de referencia. Reflexiones sobre un marco teórico" (1997)². Trabajo en el cual desarrolla los conceptos de Campo de Referencia Interno (CRI) y Campo de Referencia Externo (CRE).

Por CRI Benjamín Harshaw entiende el conjunto de elementos relacionados entre sí-acontecimientos, personajes, espacios, tiempos, ideas, situaciones sociales y políticas, diálogos, junto con las estructuras semánticas y no semánticas organizadas en el texto- que instituyen la realidad verbal al mismo tiempo que la describen» (1997, p. 130). Una obra literaria para Harshaw podría definirse "como un texto verbal que

\footnotetext{
${ }^{2}$ Recogido en la compilación de textos a cargo de Antonio Garrido Domínguez, Teorías de la ficción literaria (1997, p. 123-157). El artículo fue publicado originalmente en 1985 con el título "FictionalityansFields of Reference. Remarkson a Theoretical Framework".
} 
proyecta al menos un Campo de Referencia (CRI) con el cual se relacionan los significados del texto" (1997, p. 135). Su importancia para conformar la sustancia de un texto literario está patente en su imprescindible participación en la configuración del significado de la obra literaria33, además de establecer su coherencia interna:

Es responsable de la llamada «unicidad» de una obra literaria, basada en la fusión de todos los aspectos formales, convencionales y temáticos en una combinación individualizada de estructuras (el «mundo» fictivo del texto). Es también el portador del modo de representación: el valor expresivo, simbólico o modélico de un texto literario frente al mundo externo y el autor. (HARSHAW, 1997, p. 135).

La ventaja de referirnos a este concepto para el presente estudio es clara: CRI no es sinónimo de texto. Algunos de sus significados están relacionados con Campos de Referencia Externos (CREs) de distinta índole, tanto del mundo "real" como creencias, religión, ideologías, concepciones científicas, situaciones estereotipadas, modalidades de diálogo, etc. ${ }^{4}$. El CRI depende en alto grado de los CREs al imitarlos, evocarlos o servirse de sus referentes para construir su propio campo autónomo, proyectando aspectos de la realidad física, social y humana. Esta proyección hace que el campo externo y el interno sean paralelos, con cierto grado de semejanza, pero no de igualdad. Se aluden pero no se tocan.

Harshaw afirma la existencia de puntos de conexión que interrelacionan estos dos campos sin romper su autonomía, de esta manera "los vínculos entre los dos planos paralelos crean canales para la posible transferencia de material semántico adicional de uno hacia el otro y viceversa" (1997, p. 156). Siguiendo estos postulados y aplicándolos a la comprensión de Tirano Banderas, podemos afirmar que la yuxtaposición entre el hecho histórico referencial -la revolución mexicana y el contexto de una dictadura hispanoamericana como referentes primarios- y el constructo ficcional configurado en la novela, revela al lector una visión más compleja

\footnotetext{
3 Harshaw afirma la existencia de unos "Principios Reguladores" dentro del CRI que guían la lectura, condicionando en cierta medida la construcción del sentido en una dirección: "La autoridad latente tras el texto -es decir, el hablante o posición desde el que se presenta el texto elegido- guía nuestra comprensión, nos dice 'en qué sentido' hay que tomar el significado de las palabras" (HARSHAW, 1997, p. 133).

${ }^{4}$ Harshaw define un CRE como "todos aquellos Campos de Referencia exteriores a un texto dado: un mundo real en el tiempo y en el espacio, la Historia, una teoría religiosa, concepciones ideológicas, los conceptos de la naturaleza humana, otros textos" (HARSHAW, 1997, p. 147).
} 
de los acontecimientos que son potencialmente evocados. Consecuentemente, la concretización de la indeterminación referencial del texto por parte del lector conlleva una proyección de la perspectiva histórica de este sobre la ficción novelesca. Este acto, a su vez, provoca un proceso inverso (el "viceversa" al que alude Harshaw): la perspectiva ficcional ejerce una influencia sobre la comprensión del hecho histórico que previamente tiene el lector, iluminando así mecanismos escondidos de su configuración, pudiendo provocar, en definitiva, una apertura a significados de mayor trascendencia, una epifanía de la realidad.

Los canales de interconexión entre el CRI y CRE son, por lo tanto, de doble sentido. Estas interconexiones se producen gracias a la existencia de lo que Harshaw denomina "marcos de referencia compartidos", continuos semánticos de dos o más referentes sobre los cuales los interlocutores puedan intercambiar opiniones. Por consiguiente, la veracidad del mundo representado en relación a la realidad empírica no condiciona la interpretación de una obra literaria en cuanto objeto artístico, solo importan los marcos de referencia compartidos. Harshaw explica la importancia de este concepto para entender la amplificación del ámbito representacional del texto literario ( $y$, por ende, la superación del realismo mimético):

No se da por supuesta la existencia concreta de objetos, personajes, hechos o actitudes, sino meramente de marcos de referencia de dichas clases, a las cuales el lenguaje del texto se remite o puede remitirse, por parte de varios hablantes y de diversos puntos de vista. Estos marcos de referencia no son necesariamente estables, pueden ser construidos y reconstruidos, la evidencia lingüística puede ser complementaria o contradictoria, incompleta o falsa, incierta o inconexa, etc. (HARSHAW, 1997, p. 146)

En el caso de Tirano Banderas, nos encontramos ante una obra que enfatiza la autonomía de su CRI a través de la autorreferencialidad de su propio lenguaje. El autor crea una lengua imaginaria que es un mosaico de elementos verbales de varias regiones del mundo hispanohablante. Este idioma imposible en la realidad lingüística provoca un constante extrañamiento, ya que la mezcla de vocablos y expresiones de comunidades diferentes hacen que ningún lector pueda reconocer como suya la lengua usada en la novela. Al analizar esta lengua vemos que existen unos doscientos regionalismos, de los que más o menos la mitad son de uso habitual en varias partes 
de Hispanoamérica, pero no en España. Este dato refleja el interés de Valle-Inclán por connotar con mayor nitidez un ámbito americano en lo que parece una síntesis idiomática de todo el territorio hispanohablante.

El ensayo pionero de Speratti Piñero La elaboración artística de Tirano Banderas (1957) continúa siendo una referencia inexcusable en el estudio de la lengua de Tirano Banderas. En sus páginas la profesora argentina analiza la procedencia de las formas elegidas, contabilizando una mayoría de palabras y giros corrientes en México -más o menos un cincuenta por ciento- junto con un vocabulario utilizado en el Río de la Plata, Chile y regiones limítrofes. Ante esta variedad lingüística, para Speratti Piñero la consistente impresión de síntesis se mantiene gracias a "la hábil trabazón de voces y frases, y la no menos hábil selección de formas agudamente caracterizantes" (1957, p. 113). Sin embargo, más allá de esta caracterización, la selección de elementos lingüísticos realizada por el autor gallego parece justificarse en razones de orden estilístico, con una tendencia al exotismo pintoresco que, como ya he señalado, ha sido duramente criticada (aunque estas críticas no dejen de reconocer en ningún caso el éxito del resultado estético conseguido). La libertad con la que Valle-Inclán utiliza el lenguaje, desligándolo del uso convencional y cotidiano de la realidad social para otorgarle una verdad artística dentro de los límites de la propia obra, se ve refrendada en la frecuencia con la que encontramos palabras inventadas por el propio autor sobre la raíz de un americanismo o expresiones usadas de manera insólita, sin equivalencia fuera de la novela5.

Analizado de manera aislada, este uso del lenguaje puede parecer completamente arbitrario más allá de la novedad que supone el uso de americanismos en la prosa literaria española de la época, y el distanciamiento estético que produce el extrañamiento provocado en el lector al encontrarse con una lengua irreconocible desde su experiencia como hispanohablante. Sin embargo, la lengua de Tirano Banderas tiene una función más importante para la novela, ya que en ella se cimienta la coherencia de un campo de referencia interno sobre el cual se proyectan los significados del texto. La síntesis de lo hispanoamericano que esta lengua connota, tiene su verdadera realización dentro de la novela, al convertirse en una referencia

\footnotetext{
5 Véanse ejemplos de este fenómeno en el citado ensayo de Speratti Piñero (1957, p. 108-110).
} 
intensional que construye, al mismo tiempo que nombra, el mundo imaginario de Santa Fe de Tierra Firme. Un país ficticio cuya geografía, sociedad e historia están caracterizadas por la misma imposibilidad ontológica que aqueja al lenguaje que lo funda. De hecho, es el lenguaje el que determina el país, no al contrario ${ }^{6}$.

Es en la naturaleza de esta lengua ficticia donde encontraremos los rasgos definitorios de todos los referentes intensionales de la obra, la esencia del mundo ficcional creado por Valle-Inclán. En mi opinión, la indeterminación referencial que caracteriza la novela viene dada por este eje lingüístico. Una identificación de la lengua de Santa Fe de Tierra Firme con el español hablado en México -por poner un ejemplo del léxico más utilizado- se verá anulada por la aparición de un argentinismo o incluso por su utilización inadecuada respecto al uso establecido. Por supuesto, cualquier otra identificación con otro dialecto se verá abocada al mismo proceso de invalidación. La lengua de Tirano Banderas enfatiza en su indeterminación su carácter ficticio, su irrealidad y, en definitiva, su imposibilidad fuera de la novela. Por otra parte, la autosuficiencia respecto a los Campos de Referencia Externos no es completa.Como ya hemos comentado, un CRI tiene siempre un cierto grado de dependencia con el mundo exterior ya que, como afirma Harshaw, crea su propio "campo autónomo" mientras selecciona elementos y organiza jerarquías de la realidad. En Tirano Banderas esta selección produce un sincretismo y una indeterminación referencial que se convierten en rasgos definitorios de la autonomía de su CRI. Este hecho no anula la existencia de un CRE -la realidad americana en toda su extensión: geográfica, lingüística, histórica, social y cultural- que es proyectado paralelamente al CRI, pero los dos campos en ningún momento se tocan ya que no son idénticos.

Siendo así, los canales de conexión entre los dos campos de referencia (interno y externo) parecen cerrados en Tirano Banderas desde la propia concepción del lenguaje que construye la obra, imposibilitando una decodificación realista del texto por parte del lector. Sin embargo, Tirano Banderas consigue ese equilibrio entre autonomía artística y reflexión política de la realidad: la clave analítica que explica este

\footnotetext{
${ }^{6}$ llustrativo de este hecho son las célebres declaraciones del autor gallego: "En Tirano Banderas hay, además, la voluntad literaria de sumar al castellano castizo el vocabulario creado en la América española. Claro que para esto me ha sido necesaria la invención de una república de geografía imaginaria" (apud ZAMORA VICENTE, 1999, p. 24).
} 
hecho no está en la realidad histórica objetiva de América sino en sus esencias o, dicho de otro modo, en una clave de su configuración histórico-social que pertenece a un marco de referencia compartido: una imagen supranacional del continente expresada en la idea de una identidad común latinoamericana. Es esta una realidad abstracta, empíricamente irreal, pero que como concepto ideológico -siguiendo el marco teórico planteado por Hawshaw- pertenece al CRE de la misma manera y con la misma pertinencia que cualquier hecho histórico. De hecho, no es casual que sea precisamente en las primeras décadas del siglo XX cuando los planteamientos americanistas, en que los países del continente son concebidos como un conjunto supranacional con semejanzas históricas y culturales que les otorga una unidad diferenciada, se consolidan como una perspectiva fundamental del pensamiento hispanoamericano en la búsqueda de una identidad continental.

Carlos Pacheco (1987, p. 6o-66) enumera varios factores que considera determinantes para entender el cambio de rumbo en la narrativa de temática dictatorial en lengua española que inaugura Tirano Banderas. Entre ellos, Pacheco destaca las consecuencias de la I Guerra Mundial y la Revolución Rusa al convertir a América Latina en territorio disputado por las grandes potencias, lo que conllevó tanto un incremento del número de estudios e investigaciones sobre el continente en Europa y Estados Unidos, como un creciente interés de autores no latinoamericanos que encontraron en Latinoamérica -siguiendo la tradición de las crónicas de la conquista y la idealización romántica del territorio americano- «una atractiva veta temática, entre lo pintoresco y lo inédito» (PACHECO, 1987, p. 62). A las causas histórico-políticas Carlos Pacheco añade el contexto ideológico y cultural de las vanguardias y la crisis epistemológica del positivismo, destacando además la publicación de ensayos como La decadencia de occidente (1923) de Spengler, que dirigieron la mirada del mundo sobre territorios en los que perviviesen culturas primitivas como la precolombina, reevaluada positivamente. Partiendo de estas premisas y siguiendo los postulados expuestos por Seymour Menton (1969), Pacheco sitúa en un mismo grupo de obras a Nostromo (1904), de Joseph Conrad, Le dictateur (1926), de Francis de Miomandre, y Tirano Banderas (1926), de Valle-Inclán. Similitud basada en la condición de extranjeros de autores que se acercan literariamente al mundo americano. Esta característica conllevaría, en opinión del crítico venezolano, 
un doble distanciamiento: el geográfico-cultural, que les hace percibir lo común por encima de las diferencias locales, permitiéndoles concebir "repúblicas comprensivas" imaginarias de proporciones continentales; y el distanciamiento político-social, que les permite manejar la realidad dictatorial hispanoamericana de una manera menos apasionada, pudiendo así elaborar sus representaciones literarias con una mayor libertad estética, sin preexistentes programas ideológicos (PACHECO, 1987, p. 62-63).

En mi opinión, si bien es cierto que el lúcido análisis del profesor Pacheco contextualiza y explica coherentemente la importancia de estas novelas en la construcción de países sincréticos americanos -o "repúblicas comprensivas" como las bautizó Seymour Menton (1969), con una gran aceptación de la etiqueta entre la crítica posterior-, consideramos que explicar Tirano Banderas a través de sus similitudes con, por ejemplo, Nostromo, sería equivocado y limitaría una total comprensión de la obra. Sin entrar a valorar la novela de Conrad, el conocimiento y perspectiva del continente americano del autor inglés no pueden equipararse, so peligro de caer en graves errores, con la de Valle-Inclán?.

El autor español viajó en varias ocasiones a tierras americanas: breves estancias en Argentina, Uruguay, Chile, Bolivia, Paraguay (acompañando a su mujer en gira por Suramérica en 1910), una escala de varias semanas en Cuba en 1893, y entre estos viajes donde Valle-Inclán conoció la geografía, la cultura y el habla local-y en definitiva la complejidad del continente- destacan especialmente por su relevancia en la conformación de una visión de lo americano las dos estancias del autor en México. En 1892-1893 pudo conocer el país gobernado por Porfirio Díaz y en 1921, invitado por el gobierno del general Obregón, tuvo la oportunidad de visitar el México

\footnotetext{
7 Juan Gabriel Vásquez, novelista colombiano fascinado por la figura del autor polaco, explica en el artículo "Viaje a Costaguana", incluido en el libro El arte de la distorsión (2009, p. 145-155), el proceso de creación del mundo ficcional de Nostromoy las referencias de las que se sirvió Joseph Conrad para su representación de un mundo sincrético americano. Además de la obvia influencia de la separación de Panamá de Colombia ocurrida en 1903 y que inspirará la invención de Sulaco, la mayor parte de las fuentes fueron textuales, destacando por su importancia tres libros: De Bogotá al Atlántico de José Pérez Triana, A Vanished Arcadia, de Cunninghame Graham, y Venezuela, de Edward Eastwick. Esto es así porque la experiencia directa de Conrad en Latinoamérica se limitaba a un breve viaje por el Caribe realizado entre 1875 y 1876, más de quince años antes de comenzar la redacción de la novela. Al diferenciar a Valle-Inclán de Conrad, no queremos comparar el mayor o menor conocimiento de la realidad americana que detentaban los dos escritores, sino subrayar las enormes diferencias de perspectiva en su relación con los países latinoamericanos.
} 
revolucionario ${ }^{8}$. Dictadura y revolución en América no sufridas en sus propias carnes, como argumenta Giuseppe Bellini (2000) al compararlo con Miguel Ángel Asturias, pero, eso sí, conocidas de primera mano, primero con pasión aventurera y romántica, después con una conciencia ideológica en penetrante búsqueda de justicia social.

Su primer contacto con el país en 1892 fue especialmente importante en la biografía del escritor al descubrir en ese periodo su vocación literaria: "México me abrió los ojos y me hizo poeta. Hasta entonces yo no sabía qué rumbo tomar" (apud DOUGHERTY, 1983, p. 23), llegó a confesar. Antes de su segundo viaje, en 1918, se muestra entusiasmado respecto a la Revolución Mexicana. Un entusiasmo proporcional al profundo rechazo de la política española en América, ante la que tomó una actitud combativa en entrevistas, declaraciones, conferencias y artículos, durante su viaje a México y, posteriormente, defendiendo una política agrarista frente al latifundismo representado por los intereses económicos del gobierno español, defensores, en opinión del autor gallego, de los propietarios "gachupines" y extranjeros. Así, en carta de 1922 a la revista España afirmaba: "Los gobiernos de España, sus vacuos diplomáticos y sus ricachos coloniales, todavía no han alcanzado que por encima de los latifundios de abarroteros y prestamistas están los lazos históricos de cultura, de lengua y de sangre" (apud DÍAZ MIGOYO, 1985, p. 76).El sentido de responsabilidad histórica y social que supuso el nuevo contacto con la realidad americana en 1921 está evidenciado en estas palabras, con toda la implicación política que cristalizará en la novela de 1926. Por otra parte, no es difícil relacionar en Tirano Banderas a los «vacuos diplomáticos» con el barón de Benicarlés ni a los "ricachos coloniales" y "prestamistas" con el personaje de Quintín Pereda. La vivencia americana de Valle-Inclán fue sin duda un factor determinante a la hora de decidirse a escribir la "Novela de Tierra Caliente".

\footnotetext{
${ }^{8}$ Esta distancia temporal entre las dos visitas no solo supone el encuentro de dos países distintos sino también dos Valle-Inclán con perspectivas muy diferentes de América. Es significativo a este respecto referirnos a la conocida anécdota del primer viaje en la que el escritor retó a un duelo al director del periódico El Tiempo por haber publicado una carta en la que se criticaba directamente a los gachupines, y compararla con las numerosas declaraciones de Valle-Inclán durante su segundo viaje en las que reprobaba la actuación de la colonia española en el país. Actitudes que podemos contrastar a su vez en la esfera literaria, comparando el orgullo hispánico del Marqués de Bradomín en Sonata de estío con el afilado ataque a la presencia española en Santa Fe de Tierra Firme que supone la representación degradada y satírica de los gachupines en Tirano Banderas.
} 
Sin embargo, el elemento que más me interesa para el presente análisis, complementario de las vivencias del escritor en el continente americano, es el de su perspectiva personal dentro del llamado "hispanoamericanismo", auténtica piedra de toque de la indeterminación referencial de la novela, y uno de los elementos constitutivos de un marco de referencia que permite una decodificación realista del texto. De hecho, parece absurdo suponer que un autor como Valle-Inclán, permanentemente atento a todo lo que constituía su circunstancia histórica personal e intensamente interesado en la realidad americana, pudiese ser ajeno al proceso ideológico y cultural del pensamiento latinoamericano que venía desarrollándose desde finales del siglo XIX. La presencia de intelectuales hispanoamericanos es constante en el ambiente cultural español (especialmente en Madrid): abundan las colaboraciones en periódicos y revistas, los viajes de compañías teatrales, la publicación y lectura de obras de autores hispanoamericanos -especialmente a partir del arribo del movimiento modernista- a los que se acoge con curiosidad y familiaridad. Entre todas estas circunstancias que ayudaban a la formación de lazos intercontinentales destaca la visita -o permanencia- en España de intelectuales y escritores que desempeñaron una función directora dentro del mundo literario de la época: Rubén Darío, Gómez Carrillo, Oliverio Girondo, Rufino Blanco Fombona, Jorge Luis Borges y Alfonso Reyes, son ejemplos de autores emblemáticos de esta atmósfera cultural que, a su vez, tampoco desconocían la obra y personalidad de Valle-Inclán9.

Esta auténtica red intelectual que compone un consistente tejido de interrelaciones entre escritores de España y de las repúblicas americanas en las primeras décadas del siglo XX, tiene como eje central la construcción de una identidad continental común a todos los países hispanoamericanos que reafirmase su singularidad respecto a los valores que definían a los Estados Unidos, nueva amenaza para la independencia americana. Esta imagen global de lo hispanoamericano tenía antecedentes en el siglo XIX (pensemos en ejemplos ilustres como Simón Bolívar o José Martí), pero su momento de arranque definitivo va a ser con la publicación y extraordinaria difusión del Ariel (1900) de José Enrique Rodó. Esta corriente intelectual

\footnotetext{
9 Véase a este respecto el estudio de Eduardo Devés Valdés, Redes intelectuales en América Latina: hacia la constitución de una comunidad intelectual (2007, p. 39-93).
} 
va a desarrollarse en torno al impulso vitalista y espiritualista (de signo teosófico, humanista, socialista o anarquista) que con una impronta americanista nutrirá el pensamiento de la época. De esta manera, la idea de hispanidad construida en estos años surge en un momento de ruptura con la corriente positivista, liberal y racionalista, preponderante en el ensayismo de décadas anteriores. De hecho, este pensamiento positivista de corte modernizador, basado en un proyecto civilizador de marcado carácter liberal-burgués, tenía a Estados Unidos como modelo triunfante. Y es precisamente frente a la cada vez más evidente amenaza que supone el vecino del norte cuando, en el deseo de construcción de una identidad exclusivamente hispanoamericana, la mirada se vuelve hacia un pasado común, para encontrar en él una genealogía que evidencie un ámbito cultural propio: la hispanidad. Y esta, a su vez, englobaría una historia mucho más amplia y abarcadora, enlazando directamente con las raíces culturales que supone la ascendencia latina. De esta manera, España, Roma y la Grecia clásica suponen el principal punto de apoyo de un programa de futuro que concibe las tierras americanas como el lugar en el que resurgirá el espíritu de la raza latina del que son herederos, dando a Hispanoamérica un potencial carácter utópico, opuesto al pragmatismo materialista de la cultura sajona estadounidense ${ }^{10}$.

Estos planteamientos tendrán una fuerte repercusión en el contexto históricocultural en el que el autor de Tirano Banderas construye su imagen de América. Baste hacer mención a dos escritores con los que Valle-Inclán mantuvo una profusa relación intelectual: Rubén Darío y Alfonso Reyes. El primero fue un insigne precursor de las ideas desarrolladas por Rodó en Ariel. Ante la amenaza anglosajona, ya en un artículo de 1898, "El triunfo de Calibán", Darío expresaba «la urgencia de trabajar y luchar porque la Unión latina no siga siendo una fatamorgana del reino de Utopía» (1998, p. 453), y defendía las raíces españolas del continente, cambiando completamente de signo la visión anterior sobre la herencia española, pasando de madrastra a madre:

Y usted ¿no ha atacado siempre a España? Jamás. España no es el fanático curial, ni el pedantón, ni el dómine infeliz, desdeñoso de la

\footnotetext{
${ }^{10}$ Eduardo Devés Valdés incide en este aspecto y afirma: "Sin duda la solidaridad que significa imaginar (reimaginar) una identidad común, así sea parcial, solo es posible en la medida que se define un enemigo común. en este sentido, el latinismo y el iberismo solo se configuran en tanto que piensan al sajón como un enemigo y, a la vez, al menos en algunos planos, como un bárbaro, como un inferior. Por cierto, dicho latinismo es, al menos moderadamente, un racismo" (DEVÉS VALDÉS, 2007, p. 52).
} 
América que no conoce; la España que yo defiendo se llama Hidalguía, Ideal, Nobleza; se llama Cervantes, Quevedo, Góngora, Gracián, Velázquez; se llama el Cid, Loyola, Isabel; se llama la Hija de Roma, la Hermana de Francia, la Madre de América. (DARÍO, 1998, p. 454)

La importancia de la estrecha relación cultural entre España e Hispanoamérica en la construcción de una identidad está ya configurada en sus elementos esenciales en las palabras de Darío, reclamando una cierta solidaridad y comunicación mutua que tendrá una correspondencia en la praxis intelectual de los años posteriores al desastre del 98.

Esta urgencia de una "América unida" tendrá en la visión humanista y utópica de Alfonso Reyes -máximo valedor de la invitación de México al autor gallego en 1921- y Pedro Henríquez Ureña -al que Valle-Inclán conoció viajando por el país americano en esa misma visita- una de las interpretaciones más coherentes de la relación de América con una cultura de estirpe latina y mediterránea, ideario que conforma el pensamiento hispanoamericano en gran medida heredero del arielismo. A esto habría que unir el conocimiento de la tradición hispánica, la continua indagación en su cultura y el sincero afecto que demostraron por España estos dos intelectuales, convirtiéndose en ejemplos paradigmáticos de una renovación generacional, temática e ideológica en la que la relación fructífera entre las dos orillas del Atlántico era posible.

Esta sintética exposición del pensamiento americanista de las primeras décadas del siglo XX en España constata la existencia de una atmósfera intelectual en la que, sin duda, Valle-Inclán estaba, en mayor o menor medida, inmerso. Sus viajes, sus relaciones con escritores hispanoamericanos, su vivo y continuado interés por el continente, convierten a Valle-Inclán en un autor que, incluso con un punto de vista extranjero, inevitablemente foráneo, no era en ningún momento ajeno a las tendencias del pensamiento americano en sus soluciones más autóctonas. Tirano Banderas, a mi modo de ver, no puede ser entendida sin tener en cuenta esta red intelectual en la que la búsqueda de unas claves de la identidad americana se convierte en la hoja de ruta de numerosos intelectuales y una preocupación esencial en sus obras que va a permanecer durante gran parte del siglo XX. El autor español ahonda en esta cuestión desde su personalísima indagación poética de la realidad y 
encuentra en la figura del dictador un camino de reflexión sobre lo americano que será frecuentemente transitado con posterioridad, configurando, por ejemplo, los componentes definitorios del subgénero denominado "novela de(I) dictador".

Esta perspectiva se confirma con la lectura de algunas de sus declaraciones posteriores a su viaje mexicano de 1921. Así, en una conferencia de 1922, Valle-Inclán arremete, como ya venía haciendo, contra la política española en México, y separa su valoración del Estado español del de la nación. En su opinión el primero estaría rompiendo "la tradición latina separándonos de América" mientras que:

La nación, en cambio, no ha sido jamás igualada por sus hechos y es como el centro de una constelación de naciones. Como Grecia fue heredera de la civilización egipcia y Roma de la helénica, alzóse España con la civilización latina y erigió ciudades y dictó leyes y difundió su idioma por América. (apud DOUGHERTY, 1999, p. 215)

Si estas palabras confirman el enraizamiento de la imagen de América en una civilización mediterránea desde una perspectiva de corte humanístico, el énfasis en la difusión del idioma como elemento que ensalza la colonización española aparece como punto de enlace con la visión americanista que representa Tirano Banderas. Valle-Inclán ya había declarado "soy ciudadano del habla española", confirmando esta preponderancia del factor idiomático como eje vertebrador de la identidad ibérica de lo americano. Como he afirmado anteriormente, la visión sincrética de América tiene en la lengua elaborada en la novela de 1926 su piedra de toque, y este uso del idioma refleja un pensamiento americanista predominante en la época, cuya pervivencia durante el siglo XX ofrece al lector las claves para una interpretación realista del texto. Es este, por tanto, el marco de referencia necesario para crear canales de conexión entre los Campos de Referencia Internos y Externos de la obra, y la vía de concretización de una indeterminación que amplía el alcance referencial de la obra a todo el ámbito hispánico ${ }^{11}$.

\footnotetext{
${ }^{11}$ Por otra parte, como no podía ser de otra manera en una obra como la del último Valle-Inclán, caracterizada por la mordacidad satírica y la intención crítica hacía los caducos valores de la España nacionalista, el uso interesado del pensamiento hispanoamericanista por parte de un determinado sector de la intelectualidad española en favor de una continuidad de la visión colonizadora de la "América española" pasa también por el filtro de lo grotesco, apareciendo representado en la novela de manera explícita en las palabras del propio tirano en conversación con don Celestino Galindo, representante de la colonia española en Santa Fe de Tierra Firme, y un grupo de adinerados gachupines: "Me congratula ver cómo los hermanos de raza aquí radicados, afirmando su fe inquebrantable en los ideales de orden y progreso, responden a la tradición de la Madre
} 
En Tirano Banderas la indeterminación referencial también alcanza al tiempo histórico ya que no existen datos que contextualicen temporalmente el relato. Aquellos que aparecen son anacronismos que, más que ofrecer unas coordenadas históricas concretas, lo que hacen es extender el tiempo referencial hasta la inverosimilitud realista: la referencia a la participación de Santos Banderas en las luchas contra los españoles en Perú (1824), la alusión a Emilio Castelar como ministro de España (1873-74) o el interés de Estados Unidos por el petróleo (1900) son una buena muestra de este procedimiento. Introducidos intencionalmente por el autor, estas referencias históricas cumplen una función en la novela equivalente a la realizada por el espacio sincrético americano, al conseguir abarcar una referencialidad más amplia de la historia del continente. En este caso la capacidad representacional de la obra es llevada a una tensión máxima, ya que la reducción extrema del tiempo narrativo pretendida por el autor (la historia narrada en Tirano Banderasestá comprendida entre la tarde del día 1 de noviembre y la mañana del día 3, menos de cuarenta y ocho horas)contrasta significativamente con la amplitud referencial de los datos históricamente verificables y la capacidad sugeridora del mundo ficcional, difícilmente ubicable en un momento específico cronológicamente. En este fuerte contraste podríamos intuir una negación de la Historia, sin embargo, lo que hace Valle-Inclán en su Tirano Banderas es negar la comprensión de la Historia a través de la reconstrucción de hechos sucesivos. Para el autor gallego, una verdadera comprensión pasa por una visión a-histórica en la que un momento decisivo es seleccionado y diseccionado hasta llegar a sus esencias más profundas, de tal manera que pueda remitir a un todo. La trascendencia del instante ilumina así las claves de la realidad histórica a través de una indeterminación que solo puede ser decodificada de

\footnotetext{
Patria" (p. 44). Es significativa la ironía que subyace de toda esta escena, de adulación y colaboración con la tiranía por parte de los gachupines, y de esa interesada referencia a "los hermanos de raza" por parte del dictador. La falsedad con la que es usada esta supuesta hermandad y origen común nace de los intereses coloniales de España en la ficticia república, mostrando así el rostro hipócrita de esta imagen de lo americano. En realidad, tanto la defensa del indio que está representada en la novela -al que Valle-Inclán da voz propiacomo el uso de americanismos en el lenguaje -léxico completamente rechazado por el purismo lingüístico de los académicos españoles de la época- responden a un rechazo de la pretendida defensa de valores de lo español sobre la autonomía de lo autóctono americano, en los que estaba oculto un interés económico que remitía a pasadas actitudes colonialistas. En este contexto, el asesinato de Quintín Pereda por parte de Zacarías el Cruzado en venganza por la muerte de su hijo (p. 166-167) se desarrolla ante el lector como un acto de justicia histórica.
} 
forma realista por parte del lector. Se trata, por tanto, de una superación de los fundamentos de la novela histórica decimonónica.

Por lo analizado hasta ahora es posible concluir que la indeterminación referencial que aparece en cada uno de los elementos constitutivos de la obra permite extender el campo alusivo del texto a un todo hispanoamericano. Lógicamente, la figura central del tirano es una parte esencial de este proceso, incluso potenciando el alcance del resto de elementos que forman el universo ficcional sincrético americano. En una carta dirigida a Alfonso Reyes, Valle-Inclán definirá Tirano Banderas como "la novela de un tirano con rasgos del Doctor Francia, de Rosas, de Melgarejo, de López, y de Don Porfirio" (apud ZAMORA VICENTE, 1999, p. 12). Esta concentración de rasgos provenientes de varios dictadores históricos convierte a Santos Banderas no tanto en un ser individual como en el representante de un arquetipo cuya reiterada constancia histórica en el continente lo aproxima más a una representación genérica de carácter simbólico-mítico que a una figura individualizada. En relación a esto, Gonzalo Díaz Migoyo, en la segunda parte de su ensayo Guía de Tirano Banderas titulada "El trasmundo de Tirano Banderas" (1985, p. 223-290), realiza una búsqueda minuciosa de datos que exploran "historias tras la ficción novelesca" (p. 223), es decir, una numerosa lista de referentes históricos que pueden relacionarse con los personajes y lugares aparecidos en la novela. Especialmente interesante para nuestro estudio son las páginas dedicadas a Santos Banderas (1985, 226-238), en las que el investigador desarrolla un análisis de los modelos que nutren la fisionomía literaria del tirano de Santa Fe de Tierra Firme. Díaz Migoyo evidencia aquí cómo todos los dictadores americanos señalados por Valle-Inclán en su carta a Reyes aportan numerosas características al carácter del personaje. De los dictadores señalados por el escritor gallego es sin duda el mexicano Porfirio Díaz el que aporta un mayor número de rasgos, factor que añade un mayor grado de coherencia al plan sincrético de la obra ya que, como ya hemos comentado, es México el referente más fácilmente perceptible en todos los elementos que constituyen el mundo novelesco. Un México, eso sí, que al pasar por el filtro de la representación sincrética, enfatiza los elementos comunes frente a las diferencias, las esencias que lo hacen inclusivamente americano más que exclusivamente mexicano. 
Por otra parte, si bien es cierto que los rasgos que definen en su forma esencial a Santos Banderas pueden identificarse con tiranos hispanoamericanos del siglo XIX y comienzos del novecientos ${ }^{12}$, hay una alusión que va más allá de este periodo y que consideramos muy significativa para entender la capacidad de amplificación referencial que posee la forma novelesca de Tirano Banderas. Se trata de la evidente presencia intertextual de Lope de Aguirre en los momentos finales y muerte del tirano protagonista. Referencia que fue percibida ya por sus primeros lectores, y que con toda probabilidad tuvo en la obra Los Marañones (1913) de Ciro Bayo y Segurola, gran amigo de Valle-Inclán, su fuente más directa. Lo más interesante para este análisis es reflexionar sobre las razones que Ilevaron a Valle-Inclán a incluir un material intertextual, de origen claramente reconocible para casi cualquier lector, en un momento tan crucial en la narración como los últimos actos en vida del tirano y las noticias sobre el destino de su cadáver ${ }^{13}$. En mi opinión, estas referencias tienen una marcada intención por parte del autor a la hora de dar un sentido determinado a la novela, ya que queda sugerida en el lector la idea de que el dictador hispanoamericano, como arquetipo, tendría su origen en las raíces ibéricas, y Lope de Aguirre sería así el primer tirano de las tierras americanas. Este hecho tiene una doble repercusión: en primer lugar, la amplificación del tiempo histórico referencial que, consecuentemente, se extiende en el pasado más allá de la independencia de las repúblicas americanas hasta llegar a la época colonial, mostrando así la capacidad alusiva que detenta el elaborado planteamiento formal de la novela, su idoneidad para absorber elementos históricamente heterogéneos sin que la obra pierda una coherencia que, en realidad, queda reforzada por este mismo procedimiento; en segundo lugar, la correspondencia lógica entre la elección de Lope de Aguirre como personaje histórico reconocible para la construcción del dictador ficticio y la perspectiva "iberoamericanista" a la que me he referido anteriormente. Valle-Inclán

\footnotetext{
12 Juan Liscano acota más los rasgos característicos de Santos Banderas al considerarlos característicos de dictadores hispanoamericanos de origen popular: "costumbres austeras, crueldad fría y calculada, tendencia a la megalomanía, sentido mesiánico, valor personal de la guerra, desconfianza, desprecio por las masas de donde provienen, carencia de sentido autocrítico. En lo político, entendimiento con las fuerzas sociales reaccionarias, con los intereses extranjeros, y menosprecio radical de todas las formas de expresión representativas de la democracia parlamentaria" (LISCANO, 2000, p. 794).

${ }_{13}$ Recordemos que el despedazamiento de los restos de Santos Banderas y el mandato de repartirlos por varios lugares del país como escarmiento coincide con el final de Lope de Aguirre. Esta referencia aparece en el último capítulo del "Epílogo" (p. 256).
} 
relaciona de esta manera, en un último giro dramático de su personaje, a los conquistadores españoles con los dictadores hispanoamericanos, a los Porfirio Díaz, Francia, Solano López, Rosas y Melgarejo con una tradición de caudillismo hispánico cuyo representante en los años contemporáneos a la redacción de la novela sería el dictador español Primo de Rivera.

La barbarie dictatorial tendría en la época colonial, por tanto, el punto de origen de este mal endémico, invirtiendo así el punto de vista positivo sobre la supuesta "latinidad" existente en las raíces de la identidad hispanoamericana para, de esta manera y en consonancia con la cosmovisión degradada y alucinada del texto, reflejar de manera esperpéntica esta misma concepción ideológica y la manipulación a la que estaba siendo sometida en España. Quizá encontremos aquí uno de los factores más importantes para determinar las causas de la controversia crítica sobre la imagen de América a la que he hecho referencia en la primera parte del presente trabajo. La vehemencia con la que Valle-Inclán critica la influencia española (pasada y presente) en América singularizaría en demasía lo peninsular dentro de un mundo específicamente americano. Aspecto que, unido al carácter caricatural-inherente, por otra parte, a la estética esperpéntica- con el que representa el mundo americano y a la obligatoria colaboración del lector a la hora de concretizar una imagen realista del texto, hacen comprensible que muchos críticos hayan visto en la obra un retrato distorsionado de la realidad americana por parte de un escritor extranjero.

Sin embargo, mi perspectiva en el presente análisis tiene una mayor vinculación con una visión crítica próxima a una interpretación de la novela en la que esta escudriña las esencias de lo americano -aquellas a las que se refería Henríquez Ureña- desde la perspectiva personal de un escritor español que conocía la realidad del continente. Valle-Inclán, a mi entender, quiso profundizar tanto en lo que tenían en común las diferentes repúblicas americanas y España en contextos de dictadura y revolución -comprimiendo además esta búsqueda en un momento decisivo de este contexto histórico: la caída del tirano- que consiguió de esta forma trascender, a través de un complejo sistema novelesco, cualquier tipo de localismo, universalizando lo americano y convirtiendo su obra en una reflexión sobre el poder autoritario. Es esta capacidad de trascendencia -y las diferentes técnicas novelescas que la posibilitan- uno de los factores cruciales que sitúan a Tirano Banderas como punto de 
partida de una radical renovación de la narrativa política de temática dictatorial en Hispanoamérica.

\section{Referencias Bibliográficas}

BELLINI, Giuseppe. El tema de la dictadura en la narrativa del mundo hispánico. Roma: BulzoniEditore, 2000.

BENEDETTI, Mario. El recurso del supremo patriarca. In:El recurso del supremo patriarca. México: Nueva Imagen, 1979. p. 11-30.

BLANCO-FOMBONA, Rufino. En torno a Tirano Banderas. La Gaceta Literaria, Madrid, 15 enero de 1927.

DARÍO, Rubén. El triunfo de Calibán. Revista Iberoamericana, 184-185, 1998. p. 452-455.

DEVÉS VALDÉS, Eduardo. Redes intelectuales en América Latina: hacia la constitución de una comunidad intelectual. Santiago de Chile: Instituto de Estudios Avanzados USACH, 2007 .

DÍAZ MIGOYO, Gonzalo (1985). Guía de Tirano Banderas. Madrid: Fundamentos, 1985.

DOUGHERTY, Dru. Un Valle-Inclán olvidado: Entrevistas y conferencias. Madrid: Fundamentos, 1983.

Guía para caminantes de Santa Fe de Tierra Firme: Estudio sistémico de Tirano Banderas. Valencia: Pre-Textos, 1999.

Palimpsestos al cubo: prácticas discursivas de Valle-Inclán. Madrid: Fundamentos, 2003.

FERNÁNDEZ DURÁN, Mercedes (2008). Novelas y dictadores en América Latina. La identidad en ficción, pensamiento y forma. Bogotá: Taller de edición Rocca, 2008.

GUZMÁN, Martín Luis.Tirano Banderas. In: DOUGHERTY, Dru. Iconos de la tiranía: La recepción crítica de Tirano Banderas (1926-2000). Santiago de Compostela: USC, 2011. p. 102-105.

HENRÍQUEZUREÑA, Pedro. La utopía de América. Caracas: Biblioteca Ayacucho, 1989.

LISCANO, Juan. Sobre El Señor Presidentey otros temas de la dictadura. In: MARTIN, Gerald (Org.). El Señor Presidente (Edición crítica). Madrid: ALLCA XX, 2000, p. 791-799.

MENTON, Seymour. La novela experimental y la república comprensiva de Hispanoamérica. Estudio analítico y comparativo de Nostromo, Le dictateur, Tirano 
Banderas y El Señor Presidente. In: LOVELUCK, Juan (ed.). La novela hispanoamericana. Santiago de chile: Editorial Universitaria, 1969. p. 230-276.

NAVASRUIZ, Ricardo. Literatura y compromiso. Ensayo sobre la novela política hispanoamericana. São Paulo: Universidade de São Paulo, 1962.

PACHECO, Carlos. Narrativa de la dictadura y crítica literaria. Caracas: Celarg, 1987.

SPERATTI-PIÑERO, Emma Susana. La elaboración artística en Tirano Banderas. México D.F.: Fondo de Cultura Económica, 1957.

VALLE-INCLÁN, Ramón del. Tirano Banderas. 15ª ed. Madrid: Espasa Calpe, 1999.

VÁSQUEZ, Juan Gabriel. El arte de la distorsión. Barcelona: Alfaguara, 2009.

ZAMORA VICENTE, Alonso. Introducción a Tirano Banderas. In: Ramón del VALLE-INCLÁN, Ramón del. Tirano Banderas. $15^{\mathrm{a}}$ ed. Madrid: Espasa Calpe, 1999.

ZULOAGA, Conrado. Novelas del dictador/dictadores de novela. Bogotá: Carlos Valencia Editor, 1977.

' Doutor em Literaturas Hispânicas pela Universidad Autónoma de Madrid (UAM). Atualmente é professor adjunto de Literatura Espanhola na Universidade Federal de Viçosa (UFV).cferrerpz7@gmail.com 